\title{
Improving Residential Buildings Performance against the Explosion Using Passive Defense RequirementsCase Study: Designing a Residential Building in Damascus
}

\author{
Alhawasli H* and Daneshjoo KH \\ Department of Architecture, Tarbiat Modares University, Iran
}

Received: May 23, 2018; Published: 制 June 11, 2018

*Corresponding author: Alhawasli H, Department of Architecture, Tarbiat Modares University, Tehran, Iran, Email: alhawaslih@gmail.com

\begin{abstract}
Because of its special situation in the Middle East, which is described as a conflict zone, Syria has been subjected to war and has suffered heavy casualties and financial losses. Nowadays, using comprehensive crisis management programs can reduce the severity and extent of damages by using effective measures. One of the most important of these measures is the use of passive defense principles as a strategy to reduce risks against various hazards and increase post-risk efficiency, which should be considered at different levels of planning, urban planning and architecture. Therefore, this article is descriptive-analytical and theoreticalpractical type that can play a significant role in achieving the goals mentioned previously. Accordingly, with the completion of necessary studies on inoperative defense and architectural requirements to be respected, architectural measures in the design of residential buildings were developed for maximum use during wartime and normal conditions. The results of the information analysis indicated that the design process of a residential building could be protected" as possible as" against the explosion based on the requirements of passive defense in an organized process. At each design stage, the impact of a new design criterion will be threatened to reduce the impact. A simple example for this method can be as follows: Step One: Landscape Design, Step Two: General Design of the Architectural Concept, Step Three: Analysis and Design of Civil Engineering, and Step Four: Designing the Systems of Coating. Based on this, a ten-story residential building in Damascus-Syria was designed talking into account the above consideration to achieve safety and security.
\end{abstract}

Keywords: Passive defense; Explosion; Residential building; Secure space; Facades opening; Building location

\section{Introduction}

Humans maintain and their survival as the main exploitation of any country, national security and increase the psychological security of citizens against threats, are the most important functional outcomes of passive defense in the construction industry. Using passive defense requirements in residential buildings reduces vulnerability and reinforces national sovereignty as its component of the principles of deterrence [1]. In order to reduce vulnerabilities and increase the safety and stability of buildings and facilities against threats and control it, it is necessary to take preventive measures by designing safe and secure buildings with passive defense considerations. The design and implementation of interior spaces of the building and their relationship with each other, and the relationship of the building with the surrounding should provide special facilities to protect people from the risks and improve the performance of the system in terms of threat and reduce its vulnerability. Among the steps to be followed; determine the geometric design of the building, the position and dimensions of the openings, access and predict the multi-functional safe, and secure space for each building. The unsuitable distribution of secure spaces in site and the open spaces in residential areas may be cause a lot of dangers to their residents in the event of a threat. By designing these spaces intelligently, it can greatly reduce the vulnerability 
of the environment in critical situations, as well as create beautiful and diverse spaces that enrich the architectural space so that these spaces work in the normal conditions in the best possible way.

\section{Methodology}

A number of methods were used in this study to be consistent with the research topics. Initially, libraries, scientific articles and research were used to achieve the rules of research theory that include: Objectives and Definition of the Passive Defense, potential risks and damages resulting from the use of car bombs and the resulting explosion wave, and the rules of passive defense applicable to blast- resistant building, determination arrange of factors that affect the stability of the design, then by selecting samples from residential contemporary around the world; descriptive and interpretative method is used, Finally, determination the requirements of passive defense in the blast-resistant building and designing a residential building in Damascus according that.

\section{Passive defense objectives and definition passive de- fense definition}

Passive defense is a set of measures done to lessen potential damage to its minimum in the event of war or major natural disasters. In other words, passive defense is the non-armed action that reduces the vulnerability of people, buildings, facilities, equipment's, documents and major arteries in the face of natural disasters or enemy's destructive and hostility acts [2].

\section{The history of passive defense}

The term "Passive defense" was first found in the book "temporary protection shelter" regarded in the activities at the headquarters of America's Army in 1954 to meet new phenomenon of intense surprise nuclear attack. Since then, the concept was developed and has found a special place over all factors related to human habitat, especially in the field of architecture and urbanism. So that, today it is considered at all levels including the design of streets, applications, and even how to make doors, windows, glasses and their locations in the buildings. Its final goal is to achieve sustainability in modern architecture and urbanism. Hence, any new technologies lead us towards sustainability in architecture and urban planning and their objectives can also be effective in passive defense. Although power is an integral part of today's cities urban facilities, intelligent systems in the production and distribution of power in the topic of "smart grids"; is a movement towards sustainable urbanization [2].

\section{Principles of passive defense}

a) Selecting the safe geographic areas of a country,

b) Determine the optimal scale of population and space activities,

c) Distribution of the functions with threats and geography,

d) Small and inexpensive construction and initiative in passive defense, e) Economic feasibility of the project,

f) Parallelism associated support systems,

g) Retrofitting structures,

h) Positioning of operations,

i) Crisis defensive management in scenes,

j) Camouflage,

k) Destruction of enemy intelligence system,

l) Concealment using natural and geomorphologic features,

m) Intuitiveness and diversity in all actions,

n) Protection of critical information systems,

o) Production of dual purpose structures [3].

\section{The nature and impact of explosions}

An explosion produces air compression and resumption; When an explosive material is initiated a very rapid exothermic chemical reaction will occur, in the progress of this chemical reaction the solids and liquids contained in the explosive compound are converting to a very high dense gas, the products of this reaction expand at a very high velocity trying to reach an equilibrium state with the surrounding air, creating what is known as "shock wave". The shock wave, which is a high compressed air, travels at a supersonic speed radially from the center of the detonation. Explosions, in general, can be visualized as spherical or hemispherical bubbles of gas, depending on whether the detonation is in the air or on ground respectively. As the expansion of the shock wave continues, pressures decrease exponentially over time; it is usually measured by milliseconds due to its short life-span, also pressures decreases over the cube of the distance because of the dissipation of energy and geometric divergence. Abstractly, explosions have two main phases; the positive and the negative phase, at the positive phase, explosions create an immediate rise of the ambient pressure toward peak overpressure also known as "incident pressure", as the shock wave expands pressure decreases towards ambient pressure. The negative phase starts once the pressure reaches ambient pressure, negative phase is usually longer and has less effect on its surrounding due to the little energy left form the ignition of the explosion [4].

In case of explosive, explosive material caused two phenomena:

a) Blast wave,

b) Fragments from the explosions (Figure 1) [5].

\section{Damage caused by the explosion in the building}

Two damages are caused by the explosion in the building: structural and non- structural damages. Structural damage in turn is divided into two types:

a) The direct damage: the blast wave which leads to local destruction at the external wall of the building, windows, columns... 
b) Indirect damage: the consequences of the destruction of the columns and beams of buildings $[5,6]$.

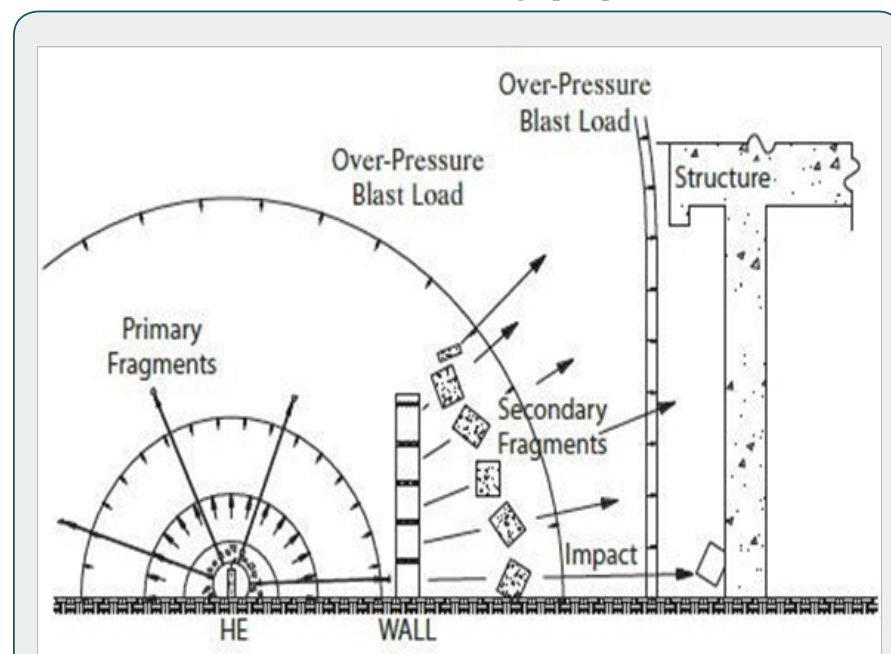

Figure 1: Detonation of a high-explosive device releases a pressure wave that creates a higher pressure demand, similar conceptually to a wind load on a building. The magnitude and duration are proportional to the scaled distance and origination of the object [6].

\section{Residential building components in passive defense considerations}

The passive defense considerations in the residential building sector are manifested in three sections of architecture, structural strength, and construction facilities. In the architecture section, it is important to pay attention to several principles such as; chosen an optimal location building, proper dispersion of the building, observance of the principles of hiding, resilience, and the interior architecture of the building. The design of the building spaces and its communications provides a special facility for rescuing people, improving building performance, and reducing its vulnerability. Table 1.
Determining the geometric design of the building, the position of openings, the way of access and propagation of the safe space as a multi-functional space for each building in times of peace and war is the responsibility of the architectural engineers.

Residential building Components in passive Defense considerations

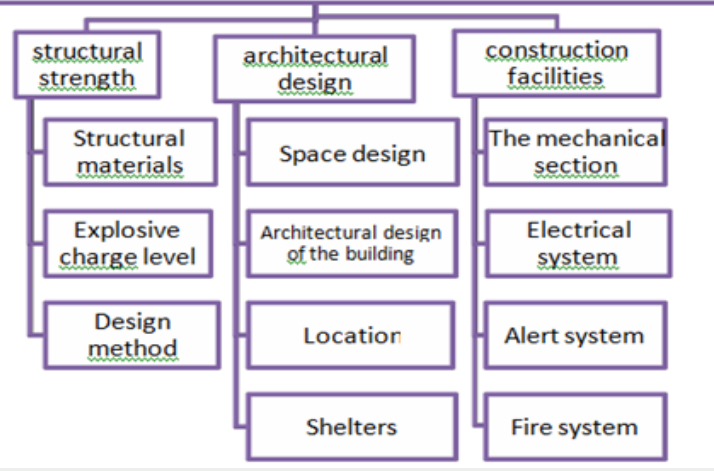

Figure 2: Residential building Components in passive Defense considerations [7].

In the structural strength section, building must be designed to withstand the blast loads. And that is the responsibility of structural engineers. In order to achieve a suitable structural system and select a suitable part of the building for a secure space, the architectural design must be consistent with the structure. In the construction facilities section, damages caused by explosion consequences must be prevented, such as gas leakage, flooding, the risk of electricity, fire, the deployment of a warning system, and limited operational capability (Figure 2) [7].

\section{Requirements of passive defense in designing the blast resistant building}

Requirements of passive defense in designing the blast-resistant building are given in Table 1.

\begin{tabular}{|c|c|c|}
\hline \multicolumn{3}{|r|}{ Requirements of passive defense in designing the blast-resistant building } \\
\hline Effective & & Requirements of passive defense in designing the blast-resistant facade \\
\hline \multirow{3}{*}{$\begin{array}{l}\text { Landscap- } \\
\text { ing design }\end{array}$} & building Locating & $\begin{array}{l}\text { a) The building location must be decentralized. } \\
\text { b) Spaces should be created between the building and the main access road, taking into account } \\
\text { differences in surfaces as possible [8]. }\end{array}$ \\
\hline & Access paths & $\begin{array}{l}\text { a) To reduce the risk of falling debris; the safe distance between the accesses paths of the building and the } \\
\text { building is at least } 1 / 3 \text { of the building height. } \\
\text { b) Minimizing interference between pedestrian and vehicle movements. } \\
\text { c) Providing several access points is required [8][9]. }\end{array}$ \\
\hline & $\begin{array}{c}\text { Open spaces and cover } \\
\text { types }\end{array}$ & $\begin{array}{l}\text { a) In the open space, edges can be created as a refuge. } \\
\text { b) Open space components can be designed based on the principle of multi- functional and flexibility [8]. } \\
\text { c) As far as possible, the sharp edges and corners should be removed from all the elements and replace with } \\
\text { soft and rounded ones. } \\
\text { d) In order to help the injured, it is recommended to customize places in open space. }\end{array}$ \\
\hline
\end{tabular}




\begin{tabular}{|c|c|c|}
\hline & & $\begin{array}{l}\text { e) When designing the building, it is suitable to design the total form in such a way that it creates many } \\
\text { different parts of the building as secure spaces and walls [5]. } \\
\text { f) The width of the stairs (at least } 1.5 \text { meters), the height of the stairs (maximum } 17 \mathrm{~cm} \text { ), the useful space of } \\
\text { stairs (at least } 30 \mathrm{~cm} \text { ), the slope of the ramp should not be more than ( }(5 \%) \text {, the width of the ramp for two } \\
\text { people must not be less than ( } 1.8 \text { meters), the materials of the floor should be rough, hard and notched [9]. } \\
\text { g) Locate decorative elements so that they cannot be exposed to the explosion wave; moreover, they must } \\
\text { not have sharp corners [8]. } \\
\text { h) The use of evergreen trees such as pine and shrubs such as "shemshad" is recommended because, as a } \\
\text { result of the energy of the explosion wave, a potential and kinetic energy in Plants become, which can be a } \\
\text { factor in reducing the effect of the explosion on the facade of the building [4]. }\end{array}$ \\
\hline & Infrastructure systems & $\begin{array}{l}\text { a) The distance between parking and the secured area around the building must be taking into account } \\
\text { so that the fire does not spread to the buildings if it is ignited. Also, for reservoirs, a suitable location with } \\
\text { protective measures, even if lower than ground level or buried, is required. } \\
\text { b) Appropriate precautions such as burial of gas pipes at appropriate depths and automatic cut-off valves } \\
\text { and other requirements are required. Avoids the passage of power cables hanging in the air [9]. }\end{array}$ \\
\hline \multirow{4}{*}{$\begin{array}{l}\text { Building } \\
\text { design }\end{array}$} & Structural system & 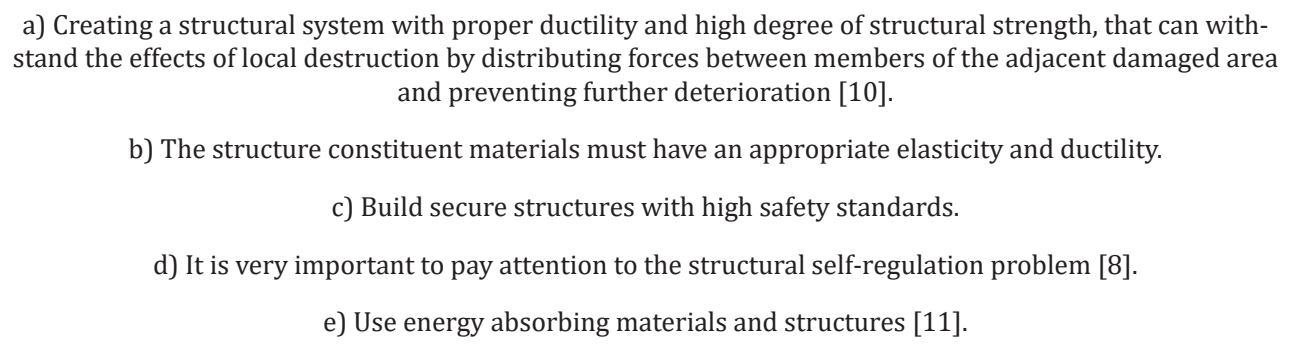 \\
\hline & $\begin{array}{l}\text { Three dimensional build- } \\
\text { ing form }\end{array}$ & $\begin{array}{l}\text { a) Vertical section of the building: In the case where the facade of the building decreases in proportion to its } \\
\text { height, it behaves more appropriately than other modes. } \\
\text { b) Cross-sectional area : Reducing the cross-sectional area of the primary form by increasing the height to } \\
\text { achieve a stable and resistant to explosion wave. } \\
\text { c) The staircase shape of the building can have a great effect in preventing the debris falling. } \\
\text { d) The form should be integrated; natural forms may be appropriate options. } \\
\text { e) Open or graded angles are less effective than winding or sharpness angles in exacerbating the effect of the } \\
\text { explosion wave [4]. }\end{array}$ \\
\hline & $\begin{array}{l}\text { Exterior façade of } \\
\text { building }\end{array}$ & $\begin{array}{l}\text { a) Creating terraces and indoor balconies in front of the main building spaces. } \\
\text { b) The balconies must be slightly spaced inside the external wall of faced, preventing the glass from being } \\
\text { thrown out. } \\
\text { c) Concrete is a suitable material for explosive structures. } \\
\text { d) Exterior facade with laminated cement is suitable. } \\
\text { e) Concrete prefabricated facades are also very suitable for explosion. } \\
\text { f) The minimum wall thickness of the reinforced concrete is } 200 \text { mm in position. } \\
\text { g) Recommendation to use vegetation on the outer walls. } \\
\text { i) we can use the sacrificial fill walls that are false and are used as the second shell on the building levels. } \\
\text { j) Connecting external walls to the structure must be firm. } \\
\text { k) Exterior walls are arranged and armed with two-sided armed building materials for both horizontal and } \\
\text { vertical spans. } \\
\text { l) An armed wall is used as facade elements or side barrels, dual with a steel or concrete frame (parallel to } \\
\text { the force of the explosion). } \\
\text { m) Using loose and friable elements in the building facade is not allowed [4]. }\end{array}$ \\
\hline & Openings & a) Being in-depth. \\
\hline
\end{tabular}




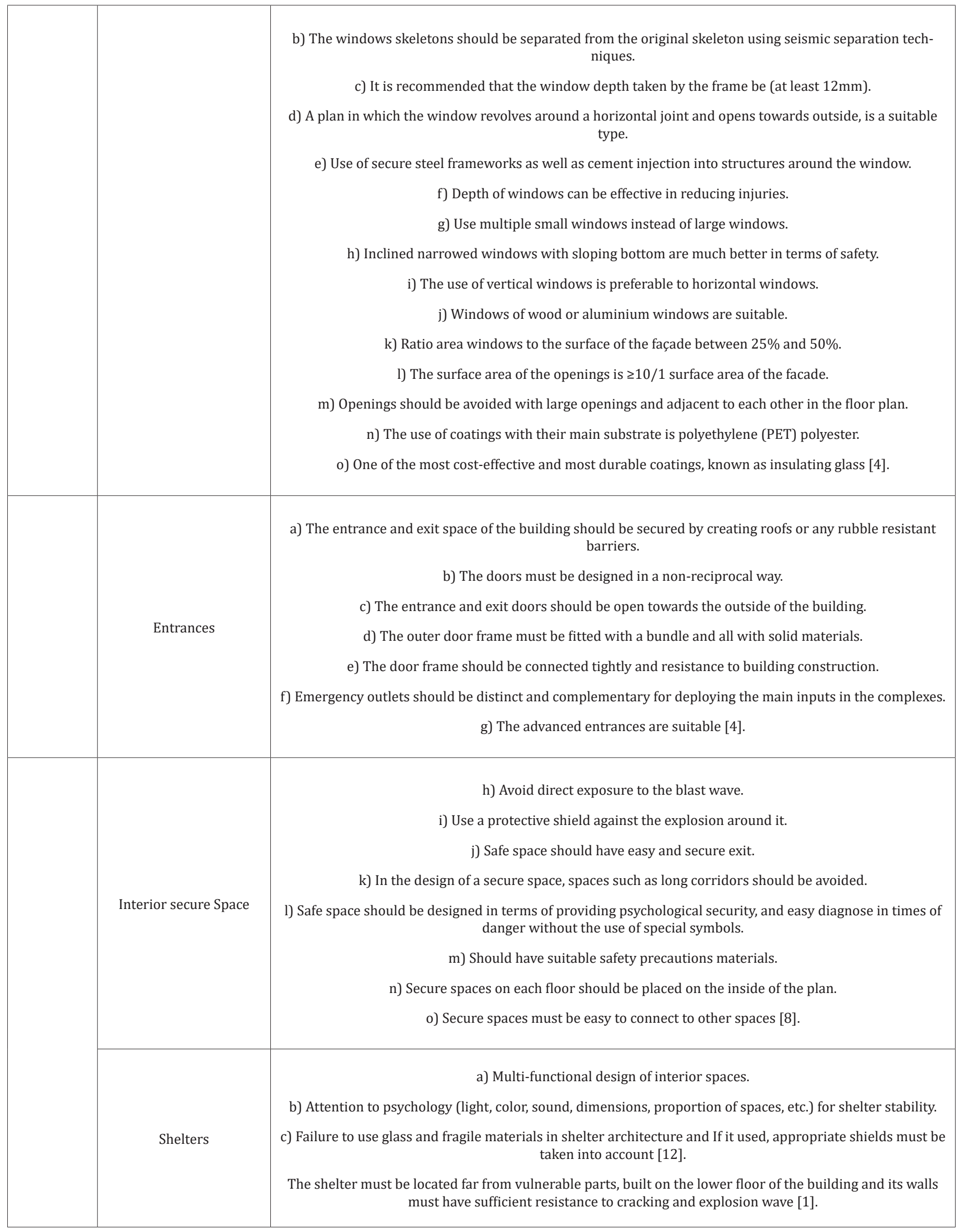




\begin{tabular}{|l|c|c|}
\hline & $\begin{array}{c}\text { a) Avoid using materials that cause cracking in the interior walls. } \\
\begin{array}{c}\text { Interior architectural } \\
\text { design }\end{array}\end{array}$ & $\begin{array}{c}\text { b) It is very important to take into account the psychosocial aspects, especially artificial colour and light in } \\
\text { the interior design of shelters, especially in underground security and shelters [13]. } \\
\text { In the ovall design of the spatial-functional program, the safe spaces of the building should be distin- } \\
\text { guished from other spaces [8]. }\end{array}$ \\
$\begin{array}{c}\text { c) Avoid using separate components such as (walls, ceilings and false floor), and in the case of using walls } \\
\text { that are detachable, they must be completely attached to the structure of the building [1]. }\end{array}$
\end{tabular}

Site and model definition: Many features have been taken into account in the process of selecting the design site, such as: the security importance of the area, being a new urban development area, and the potential exposure of various Terrorist operations [8,9]. The design selected area is located in the southwest direction of Damascus with a distance of (6 to 8 ) $\mathrm{km}$ from its center. The site dimensions are: $\left(56^{*} 61\right) \mathrm{m}$. The site area is approximately (3400) $\mathrm{m} 2$, the width of the street is opposite: (38) m (Figure 3).

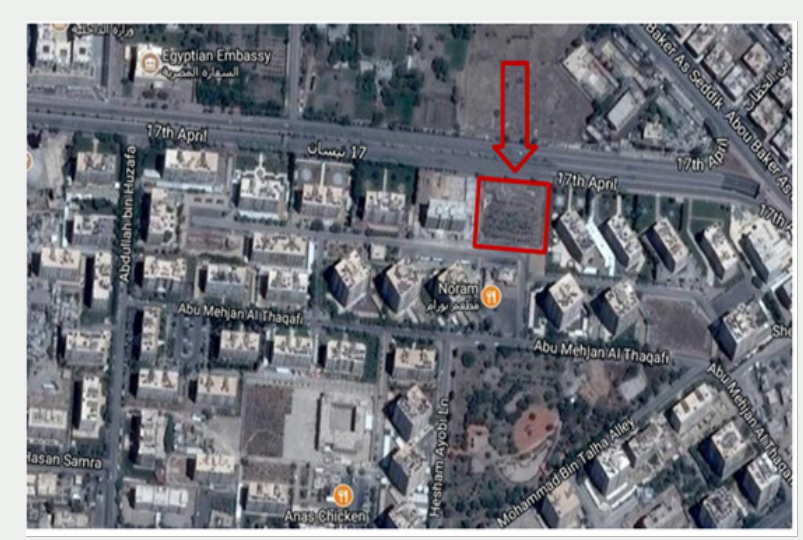

Figure 3: The site of design, Damascus "Kafar sosa" area.

The designed model is one of the models of modern residential building in Damascus, in "Kafar sosa" area. The plan is six apartments with an area about of 1000 square meters per frequent floor, Building with two entrances and each apartment in the frequent floor has two bedrooms, up ten floors to the model. This model is distributed in the general location so that achieves ventilation and the good lighting, for most of the rooms and it has a great advantage and integration between the old and the modern architectural design, where the facades reflect the spirit of heritage and add a bit of intimacy to the configuration in general (Figures 4-6).

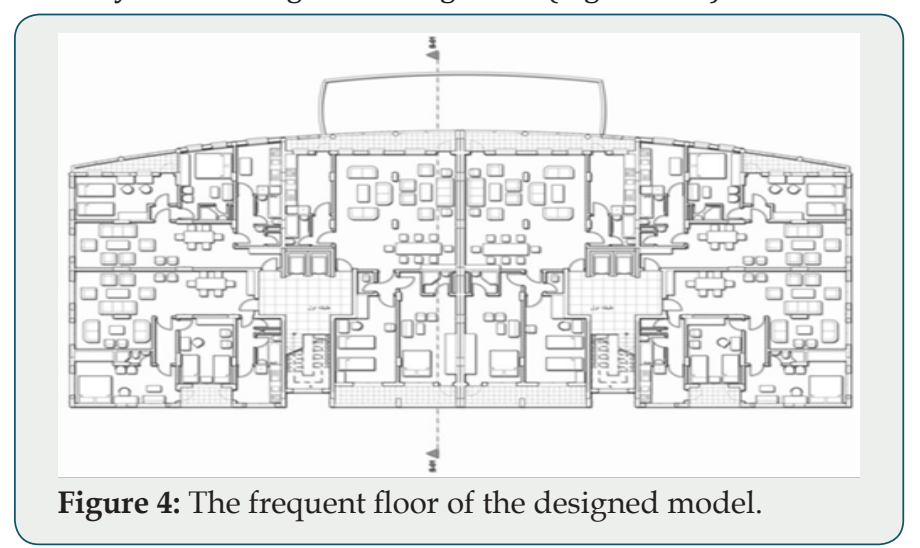

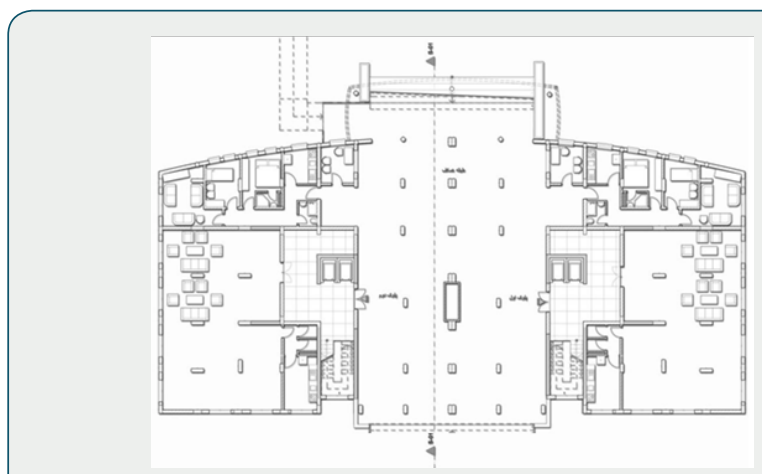

Figure 5: The ground floor of the designed model.

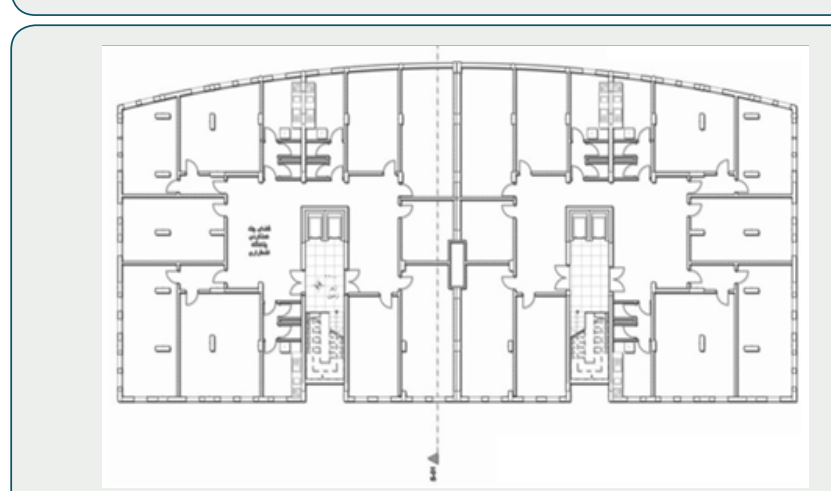

Figure 6: The underground floor" shelter floor" of the designed model.

\section{Results}

The main goal of this article is to combine all passive defense tools alongside each other in order to achieve a residential design to protect the people living in this building, and avoid increasing casualties and number of deaths caused by explosion. In the designed model, with respect to the interior design of spaces; multi-functional interior spaces with taking into account the psychosocial and security aspects whether in original spaces, security spaces or even shelters in the underground floor, have been observed significantly [10]. And avoid using separate components such as (walls, ceilings and false floor). In the facade design phase; the natural stone was used in the cladding process, and the reinforcement was used in the external walls of the building, with taking into account the horizontal and vertical reinforcement of both sides of the wall, the cladding materials were installed using the iron frames on the façade. Balconies were deep in the facade to provide the necessary protection from falling and scattering debris to the outside of the building directly by reducing the chances of injury as a result. using of attached items has been avoided i.e.: glass barrier of the balconies 
that can be a negative impact because it is in itself a detachable and crashing element, causing more damage in the event of explosion, while the rest of the decorative elements were simple and modest in the facade [11].

The windows were deep in the facade, far apart and scattered, take into account the passive defense requirements regarding the opening or installation method. Approximately the opening ratio has not exceeded a half. Entrances are gone deep inside and did not open directly on the main facade. Even though the cross- sectional area of the primary form even with increasing the height was equal because of the shape of buildings prevailing in the area but the facade has the convex angles to provide the necessary protection $[12,13]$. For the site; set of points important in the final design such as: creating several and multi-functional spaces between the building and the main access road, with taking into account the difference in surfaces. Providing several access points, customize places in open space, using of green elements; the adjacent distance of evergreen trees such as pine, and shrubs such as "shemshad" for protecting building well from the impact of the potential explosion (Figure 7).

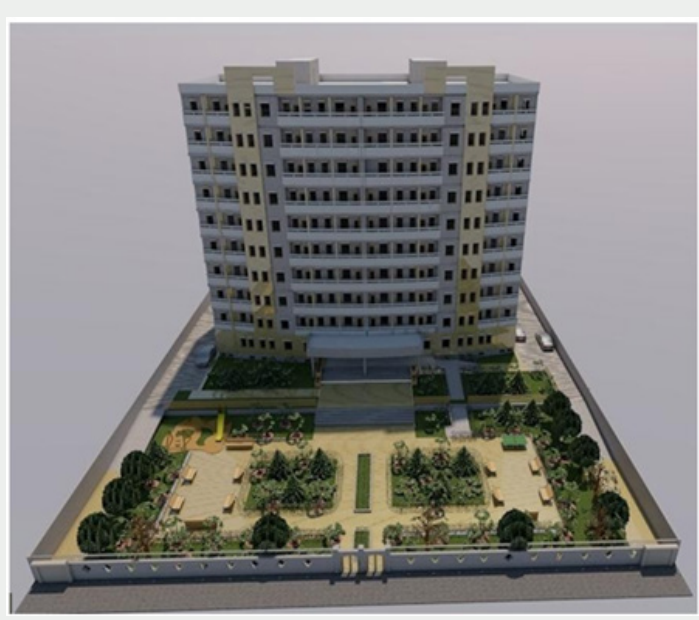

Figure 7: The site plan and the main elevation of the designed model.

\section{Conclusion}

By applying effective and practical and possibly inexpensive and multipurpose measures before the crisis reduced a large number of severity, extent of damage, and the risks losses (military and non-military, nature). Applying passive defense principles as a solution to reduce the dangers against various risks and increase efficiency when dealing with risk is one of the most important measures which should be taken into consideration at different levels of planning and different regional, urban and architectural aspects [1]. Security-oriented design of buildings involves a number of decisions to be made even before embarking into quantitative design computations. These decisions are intuitive and qualitative, but have significant impact on the level of protection finally achieved.
In particular, the architectural aspects of design of a building lend themselves to a number of such decisions. Often, the cost involved in implementing these architectural aspects is small, if implemented in the early stages of design. For this reason, consultants with specialization in security-oriented design must participate from site planning through to building finishing. Three aspects come under the purview of architectural considerations, namely architectural configuration, functional planning and non-structural elements. If not accounted for, each of these aspects can result in a major deficiency of the structure [14].

\section{References}

1. Tonbakozadeh M (2014) Building Architecture Security from the Passive Defense Perspective and humanities. pp: 427-441.

2. Jourshari SR, Kalantari NNP (2015) Creating Passive Defense System By Using Smart Materials in Sustainable Buildings. Cumhuriyet Science Journal 36(4): 1206-1212.

3. Mousavi SH (2015) The Importance of Passive Defense in National Construction with the Focus on its Significance for Engineers. Current World Environment 10: 588-593.

4. Daneshjoo KH, Alhawasli H (2017) Response Analysis of Residential Contemporary Facades to the Passive Defense Requirements for Explosion Resistance Case Study: Residential Building Facade in Damascus. J Archit Eng Tech 6: 213.

5. Khosravi F (2015) Architectural Considerations of Building Control of Pumped Oil Stations with passive Defense Approach. Quarterly Journal of Passive Defence pp: 77-99.

6. Naito C (2011) Blast-Resistant Design Considerations. Lehigh University, USA.

7. Rahmati, Jamshidi (2015) Evaluation of urban housing components for passive defense planning. Planning and space logistics 19: 2 .

8. Tahoeon Shapur (2009) Draft Twenty-first Non-Acting Passive Defense Regulations, Tehran: Publication of the Research Center for Building and Housing.

9. Farzam Shad, Mustafa (2011) Considerations for the design of open spaces for residential use with inactive approach, the first scientificresearch conference on urban planning and architecture with the passive defense approach, articles and lectures presented. Tehran, Malek Ashtar University of Technology, Iran.

10. Nairi, Arash (1392) Analysis and Design of Buildings against the Impact of Explosions. Malek Ashtar University of Technology Publishing, Tehran, Iran.

11.Gebbeken Norbert, Doge Torsten (2010) Explosion ProtectionArchitectural Design, Urban Planning and Landscape Planning. International Journal of Protective Structures 1(1): 1-21.

12. Mokhtari (2015) Requirements for Architectural Design of Public. Shelters with Inactive Passive Approach. Journal of Promotion of NonOperating Defense 6(3): 1-14.

13. Shahsavari (2015) Explaining the principles and considerations of urban defense and the approach of passive defense with an emphasis on the cellularization of cities. Journal of Urban Management 14(38): 371-390.

14. Kanpur II (2007) IITK-GSDMA guidelines on measures to mitigate effects of terrorist attacks on buildings. National Information Center of Earthquake Engineering Department of Civil Engineering Indian Institute of Technology, Kanpur, India. 
(c) This work is licensed under Creative

To Submit Your Article Click Here: $\quad$ Submit Article

DOI: 10.32474 /TCEIA.2018.02.000138

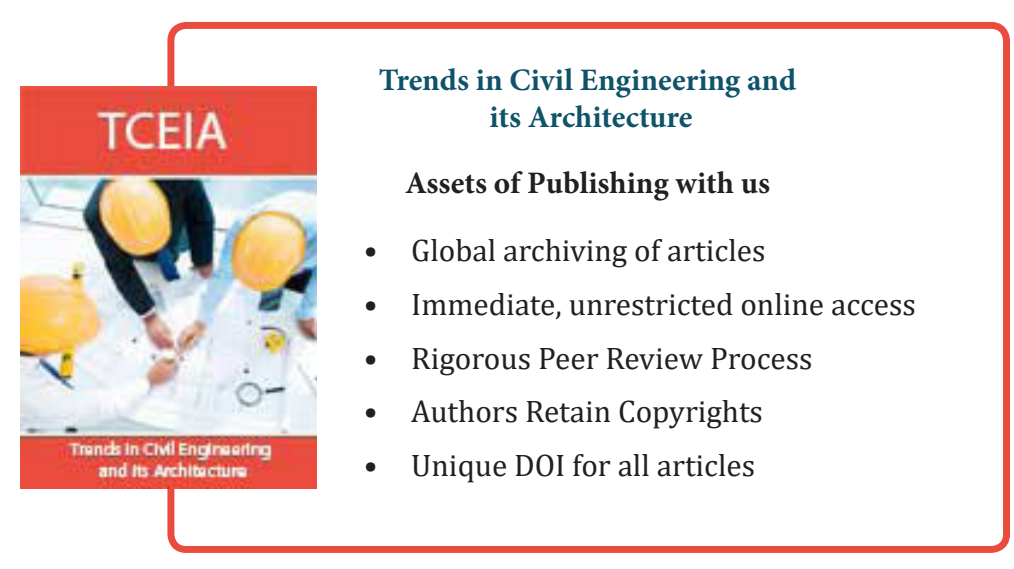

